\title{
BioMedicine
}

\section{LASER-ASSISTED TOOTH EXTRACTION IN PATIENTS WITH IMPAIRED HEMOSTASIS}

Follow this and additional works at: https://www.biomedicinej.com/biomedicine

Part of the Dental Public Health and Education Commons, Health and Medical Administration Commons, Hemic and Lymphatic Diseases Commons, Life Sciences Commons, Medical Sciences Commons, and the Oral and Maxillofacial Surgery Commons (c) (i)

This work is licensed under a Creative Commons Attribution 4.0 License.

\section{Recommended Citation}

Larionova, Elena Dr.; Diachkova, Ekaterina Dr.; Morozova, Elena Prof.; Davtyan, Albert Dr.; and Tarasenko, Svetlana Prof. (2021) "LASER-ASSISTED TOOTH EXTRACTION IN PATIENTS WITH IMPAIRED HEMOSTASIS," BioMedicine: Vol. 11 : Iss. 2 , Article 8.

DOI: $10.37796 / 2211-8039.1072$

This Original Articles is brought to you for free and open access by BioMedicine. It has been accepted for inclusion in BioMedicine by an authorized editor of BioMedicine. 


\section{LASER-ASSISTED TOOTH EXTRACTION IN PATIENTS WITH IMPAIRED}

HEMOSTASIS

\section{Cover Page Footnote}

We appreciate the help of our collegue and the University 


\title{
Laser-assisted tooth extraction in patients with impaired hemostasis
}

\author{
Elena Vladimirovna Larionova*, Ekaterina Yurievna Diachkova, \\ Elena Anatolievna Morozova, Albert Artemovich Davtyan, Svetlana Viktorovna Tarasenko
}

Department of Oral Surgery of E.V. Borovskiy Institute of Dentistry of I.M. Sechenov First Moscow State Medical University (Sechenov University), Russia

\begin{abstract}
Introduction: The provision of efficient dental care to patients with hemostatic disorders is tied to difficulties and problems, such as prolonged bleeding after or during surgical manipulation.

Aim: was to increase the efficiency of oral surgery in patients with thrombocytopenia with the use of erbium laser on different stages of tooth extraction.

Methods: Patients $(n=96)$ were selected for tooth extraction on an outpatient basis: patients with confirmed thrombocytopenia (age $44 \pm 15.4,19-74)$ were included in the $1^{\text {st }}$ group, and patients without impaired hemostasis (age $47.6 \pm$ $15.3,19-81)$ were included in the $2^{\text {nd }}$ group $(p>0.05)$. In the 1 st group, operation with the use of erbium laser with with a wavelength of $2490 \mathrm{~nm}$ in a noncontact mode was performed in two stages: separation of a circular tooth ligament and curettage of the socket after tooth extraction. In the $2^{\text {nd }}$ group (control), the treatment was provided according to a traditional algorithm. Before the operation, the lab blood tests for thrombocytes were performed in both groups; moreover, for the 1st group, the duration of bleeding and total coagulation were evaluated. In the postoperative period, pain and edema of soft tissues and hemostasis duration were assessed in both groups.

Results: According to the results of our research, the use of erbium laser in the $\mathbf{1}^{\text {st }}$ group allowed us to decrease hemostasis duration compared with the control group of patients $(80.9 \pm 35.9$ and $175 \pm 67.5$ sec, $p<0.01)$ and reach the similar probability of postoperative bleeding after tooth extraction $(p<0.5)$. Pain and edema of soft tissues in dynamics after operation were less in the $1^{\text {st }}$ group ( $\left.\mathrm{p}<0.001\right)$.

Conclusion: Application of erbium laser is an up-to-date method that can be successfully used in surgical treatment in patients with hemostasis failure for bleeding and other postoperative complications prevention and stimulation of the alveolar epithelialization after tooth extraction.
\end{abstract}

Keywords: bleeding, erbium laser, hemostasis, platelets, tooth extraction, thrombocytopenia

\section{Introduction}

$\mathrm{C}$ urrently, there are difficulties in providing dental care to patients with diseases of the hematopoietic system, including a lack of preventive orientation and planning in treatment, inadequacy of its quality to modern requirements, and low level of dental hygiene education and patient awareness. All these problems dictate the need to address the issues of providing dental care to patients with this pathology [1-6].
When performing surgical interventions in patients with impaired platelet hemostasis, in conditions such as thrombocytopenia, thrombocythemia, and thrombocytopathy, there is a risk of intra- and postoperative bleeding and hematoma formation, due to a significant decrease or possible increase in platelet count, or a pathological change in platelet function [7-9]. First-line drug treatment in patients with the autoimmune impaired hemostasis alike primary thrombocytopenia includes the appointment of glucocorticoids or cytostatic medicine, which can lead to the development of

Received 5 May 2020; accepted 3 September 2020.

Available online 1 June 2021

* Corresponding author at:

E-mail address: emletter@mail.ru (E.V. Larionova). 
immunosuppression and influence the repair and regeneration processes, contributing to the occurrence of postoperative inflammatory complications [10-16]. In most cases, dental interventions are usually carried out after preliminary medical preparation, "under the cover" of such hemostatic drugs as, for example, cryoprecipitate, freshly frozen blood plasma and others [17-22]. The development of effective substitution therapy and nonspecific drugs can successfully prevent and treat almost all types of bleeding, and thereby achieve a qualitatively new standard of living for hematological patients. However, in urgent cases, it is necessary to provide surgical dental care without prolonged medical preparation [23-26].

Laser technologies are now widely used methods of treatment of diseases and in medicine, also in dentistry. Dentists can use different lasers according to their modes and wavelengths for different purposes: Remark: Please replace with "ablation of hard tissues of tooth; surgery of oral mucosa, particularly in chronic conditions like ulcers and tissues of periodontum; endodontic dentistry; and dental implantation." [27, 28].

Earlier, dentists used only the physiotherapeutic effect of the low-intensity lasers, but with the development of medicine, the opportunities of laser application are also widening. The diode laser is characterized by the rather high profile of safety without the damage of the adjunct area besides target points that allow us to use it even during tender manipulations in dentistry as endodontics and periodontics treatment, but it does not show sufficient antibacterial effect in all cases. In oral surgery during the last years the use of high intensity lasers, such as erbium, is considered as an alternative to cutting and rotational instruments but can lead to some unpleasant outcomes, such as tissue overheating. Characteristics of appropriate situations for the use of laser during surgery include the maintenance of a good sterile zone, avoidance of active bleeding, avoidance of disturbance of entire neighborhood structures in the oral cavity. The decrease in the loss of marginal periodontium and in the risk of scar formation after using lasers was noted, particularly in comparison with the traditional scalpel techniques [29]. Also, the erbium laser can create conditions for speeding wound epithelization, stimulation of local immune system elements and reduction of pathogenic microorganism activity [30].

Laser technology used in dentistry allows decreasing the risk of possible complications, duration of manipulation, the level of patient fear on dental visit as well as achieving good postoperative results, which is particularly important for patients with impaired hemostasis because they are scared of possible extensive bleeding and need for hospitalization.

The aim of the study was to increase the efficiency of surgical dental treatment of patients with platelet hemostasis disorders using laser technologies.

\section{Methods}

As part of this study, an examination and surgical treatment of 96 patients requiring surgical dental care were performed during 6 years since 2014 at the Department of Dental Surgery of the Institute of Dentistry of Sechenov University, Moscow, Russia and Department of Maxillofacial Surgery of Moscow State Medical Dentistry University.

This study was approved by Local Committee of Ethics №6 on 02/22/2011, № 14-19 on 11/13/2019 and performed according to the principles outlined in the Declaration of Helsinki. We received the patients' consent for using the results of research, $X$ ray, and photos of the operation.

Two groups of patients were formed: in the $1^{\text {st }}$ group I $(n=48)$ patients had impaired platelet hemostasis. Surgical dental care for these patients was provided using an erbium laser with a wavelength of $2940 \mathrm{~nm}$. The $2^{\text {nd }}$ group (control group, $\mathrm{n}=48$ ) consisted of patients without hemostatic disorders. Surgical dental treatment was performed using traditional methods.

Inclusion and exclusion criteria for participant enrolment in our research are listed in Table 1.

All patients underwent standard dental and radiological examinations. When examining the oral cavity, attention was drawn to the presence of foci of

Table 1. The inclusion and exclusion criteria for patients.

\begin{tabular}{lll}
\hline Criteria & Inclusion & Exclusion \\
\hline Age, years & $>18$ & $<18$ \\
Thrombocytes $/ \mu \mathrm{L}$ & Approved thrombocytopenia & Reference means \\
& $(<100)$ & Periodical \\
Medical treatment of thrombocytopenia & Permanent & - \\
Indications for oral surgery & Present & Present \\
Other comorbidities, besides thrombocytopenia & Absent & Bad \\
Compliance & Good & \\
\hline
\end{tabular}


chronic infection (carious lesions, complications of caries), the condition of periodontal tissues, the presence of hemorrhagic syndrome manifestations in the oral cavity (bleeding of the mucous membrane, petechiae, and ecchymosis), and oral hygiene index.

As a laboratory preoperative examination in patients with hemostatic pathology, the following methods were performed: a common blood test (hematology), coagulogram and express diagnostic methods for determination of bleeding time according to Duke (a method that involves a stab incision in patient's cleaned finger or earlobe with a lancet and later, using a timer, the blood is blotted twice a minute; time is measured in minutes) [31] and time of total blood coagulation according to Morawitz (a drop of blood taken from a finger or earlobe is applied to a glass slide; turning on the stopwatch, a thin glass capillary is lowered into a drop of blood every 20-30 seconds; coagulation time is determined at the time the first thin filament of fibrin appears when the capillary is pulled from a drop of blood) [32].

Patients with platelet hemostasis disorders underwent surgical treatment under local anesthesia on an outpatient basis and according to indications: tooth extraction (due to the chronic apical periodontitis or its exacerbation and acute or chronic pericoronitis with the tooth dystopia, followed by treatment of the extracted tooth sockets with laser radiation in a non-contact mode).

In patients with hemostatic disorders, we used an erbium laser with a wavelength of $2940 \mathrm{~nm}$ (Fig. 1A), which can be used when working with both soft and hard tissues. Among all the operations we performed, the most frequent was the tooth extraction.

When working with soft tissues, we used radiation energy of $300 \mathrm{~mJ}$ and a frequency of $10 \mathrm{~Hz}$ without water-air cooling to coagulate the walls of the vessels of soft tissues and ensure hemostasis. Work on hard tissues was performed by an erbium laser in a noncontact manner in a pulsed mode, the radiation energy was $250 \mathrm{~mJ}$ and the frequency was $15 \mathrm{~Hz}$ with water-air cooling. When performing tooth extractions, the tooth alveolus was treated with an erbium laser in the hard tissue mode, and then the surrounding soft tissues of the adjacent gums and periodontal ligaments were treated with radiation from the erbium laser in the corresponding mode (Fig. 1B-D). This set was chosen according to the results of our previous experience of treatment of a patient with the same co-morbidity but in the case of periostitis [33]. Local hemostatic drugs were not used; preoperative drug preparation of patients was not performed. The control of hemostasis was carried out within 40 minutes after the intervention. In patients of the control group, surgical treatment was carried out according to the traditional method, without the use of laser technology.

On days 1 and 3 of the postoperative period, the severity of pain was evaluated using a digital rating scale (Numerical Pain Scale) (0-4 points: 0 indicates absence of pain, 1 lack of pain, 2-mild pain, 3moderate pain, and 4- severe pain) and visual assessment of collateral edema (0-4 points: 0 indicates absence of edema, 1 lack of edema, 1 - mild edema, 2-moderate edema, 3- severe edema). We supposed the possibility of postoperative bleeding in points ( 0 indicates absence of bleeding, and 1 indicates bleeding and requiring treatment).

\subsection{Statistics}

We checked normality with the ShapiroWilcoxon test and used methods of non-parametric statistics because of the lack of normality of distributions. We compared the two groups according to each criterion with the help of Mann-Whitney test imagining that the null hypothesis $\mu_{0}$ was not equal to $\mu_{1}$ when $\mu_{0}$ "there were no differences between the groups". We evaluated the differences in dynamics criteria, pain, and edema with the help of Kruskal-Wallis test and the probability of postoperative bleeding in both groups using the chisquare test. We analyzed the strength of correlation between different criteria and methods of treatment in both groups with the Pearson correlation coefficient in program $\mathrm{R}$ (designed by Ross Ihaka and Robert Gentleman, licensed in $\mathrm{R}$ Foundation, project GNU GPL, 2020, version 3.6.1) with installed packages ggpubr and ggplot2.

\section{Results}

The age of patients in both groups was similar and varied from 19 to 74 years in the $1^{\text {st }}$ group and from 19 to 81 years in the $2^{\text {nd }}$ group $(U=1020.5, p>0.05)$.

All patients of the $1^{\text {st }}$ group had anxiety and fear not only of the upcoming treatment but also of the examination. Patients were not afraid of the manipulations, but of bleeding during the intervention and in the postoperative period. While the medical history, it was found that $11(22.9 \%)$ patients of the first group noted prolonged bleeding, sometimes up to 2 days, after previous dental interventions (tooth extraction and professional oral hygiene). In two cases $(4.2 \%)$, it was precisely such type of bleeding that was the first manifestation of a disease of the hematopoietic system two $(4.2 \%)$ patients who 

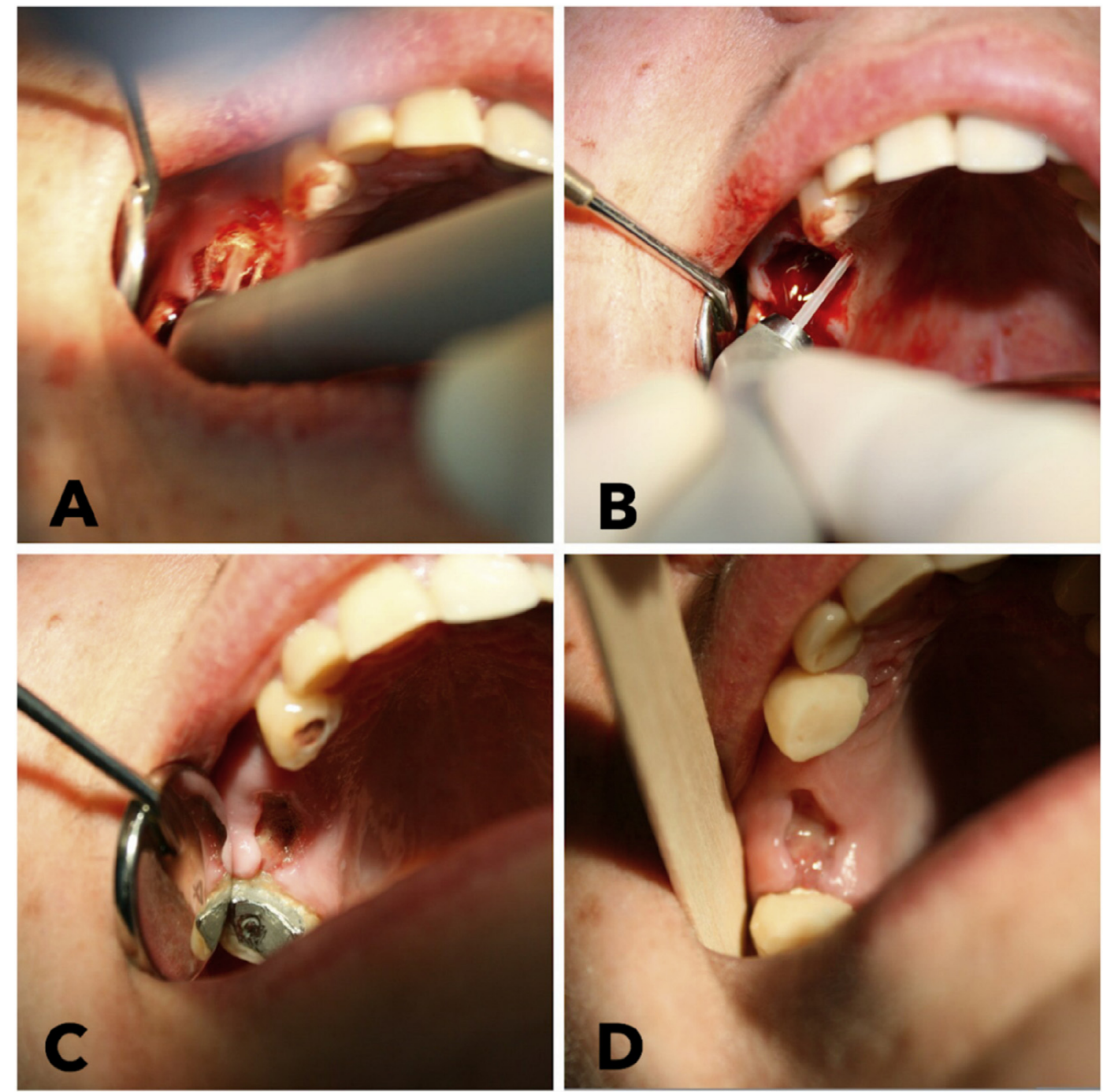

Fig. 1. Tooth extraction with erbium laser and postoperative view. (A) Separation of a circular tooth ligament using radiation of the erbium laser with the energy of $300 \mathrm{~mJ}$ and a frequency of $10 \mathrm{~Hz}$ without water-air cooling around the root of tooth 1.6. (B) Curettage of the socket of the extracted tooth 1.6 root using an erbium laser with the energy $250 \mathrm{~mJ}$ and frequency $15 \mathrm{~Hz}$ with water-air cooling. (C)The socket of the extracted tooth 1.6 root. (D) The socket of the extracted tooth 1.6 root on the $3^{\text {rd }}$ day after surgery.

underwent surgery were hospitalized with alveolar socket bleeding for emergency medical care.

We observed unsatisfactory oral hygiene in all patients with platelet hemostasis pathology since they were afraid of trauma to the gingival mucosa and subsequent bleeding during teeth brushing.

The characteristics of both groups are shown in Table 2.

Table 2. Characteristics of hemostasis and age of patients in the $1^{\text {st }}$ and $2^{\text {nd }}$ groups.

\begin{tabular}{lll}
\hline Characteristic & $\begin{array}{l}1^{\text {st }} \text { group } \\
\text { Mean } \pm \text { SD } \\
\text { (Median, Min-Max) }\end{array}$ & $\begin{array}{l}2^{\text {nd }} \text { group } \\
\text { Mean } \pm \text { SD } \\
\text { (Median, Min-Max) }\end{array}$ \\
\hline Age, years & $44 \pm 15.4$ & $47.6 \pm 15.3$ \\
& $(42,19-74)$ & $(49,19-81)$ \\
Trombocytes $/ \mu \mathrm{L}$ & $70 \pm 27$ & $304 \pm 114$ \\
& $(65,1-140)$ & $(315,200-435)$ \\
Morawitz coagulation time, min & $7,6 \pm 0.67$ & - \\
Duke bleeding time, min & $(6.6,4.1-17)$ & - \\
& $5,38 \pm 2.6$ & \\
\hline
\end{tabular}

*SD-standard deviation, p-p-value. 
Table 3. Characteristics of postoperative hemostasis in the $1^{\text {st }}$ and $2^{\text {nd }}$ groups.

\begin{tabular}{llll}
\hline Characteristic & $\begin{array}{l}1^{\text {st }} \text { group } \\
\text { Mean } \pm \text { SD } \\
\text { (Median, Min-Max) }\end{array}$ & $\begin{array}{l}2^{\text {nd }} \text { group } \\
\text { Mean } \pm \text { SD } \\
\text { (Median, Min-Max) }\end{array}$ \\
\hline Hemostasis time after operation, sec & $80.9 \pm 35.9$ & $175 \pm 67.5$ & $P$ \\
& $(78,15-175)$ & $(170,95-300)$ & 0 \\
Postoperative bleeding, points & $0.02 \pm 0.14$ & $(0,0)$ & $<0.05$ \\
& $(0,0-1)$ & & \\
\hline
\end{tabular}

Table 4. The distribution of study patients in the $1^{\text {st }}$ and the $2^{\text {nd }}$ groups according to the severity of pain in the postoperative period.

\begin{tabular}{|c|c|c|c|c|}
\hline \multirow[t]{2}{*}{ The severity of pain } & \multicolumn{2}{|c|}{$\begin{array}{l}\text { Study group } 1^{\text {st }} \\
\mathrm{N}(\%)\end{array}$} & \multicolumn{2}{|c|}{$\begin{array}{l}\text { Study group } 2^{\text {nd }} \\
N(\%)\end{array}$} \\
\hline & Day 1 & Day 3 & Day 1 & Day 3 \\
\hline Absence of pain & $3(6.3 \%)$ & $34(70.8 \%)$ & - & $8(16.7 \%)$ \\
\hline Lack of pain & $24(50 \%)$ & $13(27.1 \%)$ & $9(18.8 \%)$ & $24(50 \%)$ \\
\hline Mild pain & $13(27.1 \%)$ & $1(2.1 \%)$ & $14(28.6 \%)$ & $14(28.6 \%)$ \\
\hline Moderate pain & $5(10,3 \%)$ & - & $17(35.9 \%)$ & $2(4.7 \%)$ \\
\hline Severe pain & $3(6.3 \%)$ & - & $8(16.7 \%)$ & - \\
\hline p-value & $<.001$ & & & \\
\hline
\end{tabular}

The platelet count in patients with thrombocytopenia ranged from single to $140,000 / \mu \mathrm{L}(70 \pm 27)$. In 16 patients $(33.3 \%)$, an increase in bleeding time according to Duke was noted. Duke express test results did not always correlate with platelet count, which suggested that the risk of bleeding was often due to functional platelet disorders. Conducting express tests immediately before surgery allowed us to assess the degree of violation of platelet-vascular hemostasis at a given time.

Drug preparation before surgery was performed only in $7(14.6 \%)$ patients with pathology of platelet hemostasis. In $3(6.3 \%)$ of them, it consisted comprised administering intravenous drugs before surgical treatment because of severe thrombocytopenia against the background of ongoing chemotherapy and the urgency of the intervention. In 4 $(8.3 \%)$ patients, drug preparation consisted of prescribing tablet forms of drugs (tranexamic acid) 3 days before surgical treatment and was due to a high risk of bleeding associated with a severe degree of hematopoietic system pathology, which is a manifestation of hemorrhagic syndrome.
During surgery, in all cases, in patients with platelet hemostasis disorders, increased bleeding from the vessels of the microvasculature of the soft tissues was defined, and the severity of bleeding was more often, but not always, correlated with the number of platelets in the peripheral blood.

The use of an erbium laser made it possible to achieve reliable hemostasis in all cases. The average value of hemostasis time when using a laser was 80.9 \pm 35.9 seconds, the minimum and maximum values were 15 seconds and 175 seconds, respectively. With the traditional intervention technique, the average hemostasis time was $175 \pm 67.5$ seconds, with the minimum and maximum hemostasis times being 95 seconds and 300 seconds, respectively $(\mathrm{p}<0.01)$.

Thus, when an erbium laser was used during the intervention, bleeding stopped in a shorter time than with the traditional method of intervention in patients without pathology of the hematopoietic system. No bleeding in the postoperative period was observed, apart from 1 case $(2,3 \%)$ associated with violations of recommendations. Hemostasis was monitored at the clinic for 40 minutes (Table 3).

Table 5. The distribution of study patients in the $1^{\text {st }}$ and the $2^{\text {nd }}$ groups according to the severity of edema in the postoperative period.

\begin{tabular}{|c|c|c|c|c|}
\hline \multirow[t]{2}{*}{ The severity of collateral edema } & \multicolumn{2}{|c|}{$\begin{array}{l}\text { Study group } 1^{\text {st }} \\
\mathrm{N}(\%)\end{array}$} & \multicolumn{2}{|c|}{$\begin{array}{l}\text { Study group } 2^{\text {nd }} \\
N(\%)\end{array}$} \\
\hline & Day 1 & Day 3 & Day 1 & Day 3 \\
\hline Absence of edema & $29(60.4 \%)$ & $40(83.3 \%)$ & $4(8.3 \%)$ & $4(8.3 \%)$ \\
\hline Lack of edema & $13(27.1 \%)$ & $8(16.7 \%)$ & $29(60.4 \%)$ & $20(41.2 \%)$ \\
\hline Mild edema & $4(8.3 \%)$ & - & $12(25 \%)$ & $10(20.6 \%)$ \\
\hline Moderate edema & $1(2.1 \%)$ & - & $3(6.3 \%)$ & $14(29.9 \%)$ \\
\hline Severe edema & $1(2.1 \%)$ & - & - & - \\
\hline p-value & $<.001$ & & & \\
\hline
\end{tabular}


According to the results of the data obtained, during operations performed using an erbium laser, pain (Table 4$)(\mathrm{H}=88.8, \mathrm{p}<0.001)$ and collateral edema (Table 5) $(\mathrm{H}=74.8, \mathrm{p}<0.001)$ were both less pronounced on days 1 and 3 after surgery.

An important fact was that patients of the $1^{\text {st }}$ group did not take non-steroidal anti-inflammatory drugs due to the absence of a pronounced pain syndrome, which was especially important in patients with hemostatic disorders and in patients with erosive-ulcerative lesions of the gastrointestinal tract. It should be noted that during surgical treatment with an erbium laser, an increase in collateral edema from 1 to 3 operating days was not observed and an increase in edema was observed only in patients of the control group. We had not found the correlation between pain and edema in $2^{\text {nd }}$ group $(r=0.15, p>$ 0.05 ) with statistical significance and found connection between these criteria in the $1^{\text {st }}$ group $(\mathrm{r}=0.54$, $\mathrm{p}<0.05)$. There was no correlation between time bleeding according to Duke and edema on the day 1 after operation in the $1^{\text {st }}$ group $(\mathrm{r}=-0.14, \mathrm{p}>0.05)$. The correlation between Morawitz time coagulation and edema on the day 1 after operation was rather weak $(r=0.29, p<0.05)$. The correlation between the number of thrombocytes in the patients of the $1^{\text {st }}$ group and postoperative bleeding was not significant $(\mathrm{r}=0.11, \mathrm{p}>0.05)$.

We also noted faster epithelization of wounds and sockets in this group of patients (on average, 2 days faster than in the $2^{\text {nd }}$ group), without signs of inflammation and without scar formation, despite the fact that in patients with diseases of the hematopoietic system, repair and regeneration potentials were reduced due to the concomitant pathology itself and the use of drugs prescribed for its treatment and correction of the condition.

\section{Discussion}

When providing surgical dental care to patients with platelet hemostasis disorders, an assessment of the risk of intra- and postoperative bleeding development is relevant. Several authors described various algorithms for preparing such patients for dental treatment - the use of thrombopoiesis stimulants and preparation using corticosteroid drugs [34-36]. It is recommended to perform simple tooth extraction with a platelet count of more than 30,000 / $\mu \mathrm{L}$, and more complex surgical interventions may be conducted with a platelet count of more than 50,000/ $\mu \mathrm{L}[34,35]$. However, these solutions require time and dynamic control of platelet count and their functional activity. At the same time, in oral surgery, we often encounter acute pain complaints and we need to perform surgical procedures without prolonged medical preparation.

Algorithms for assisting this group of patients and the results of studies conducted in this direction indicate the frequent need for surgical dental interventions in a hospital setting [34,35].

To optimize the care of patients with this pathology, we evaluated the possibility of using laser technologies on them. Dissecting the tissue, the laser beam simultaneously coagulates the vessels on the walls of the wound, contributing to hemostasis. In addition, postoperative edema is minimal, the intensity of intraoperative and postoperative pain is reduced, and patients do not experience psychoemotional stress [36-43].

In several studies, the opportunity of diodeportunity of diode and Nd: YAG laser was shown to stimulate periodontal regeneration of the tissues during the operation of tooth transplantation on the cell level because the increase in calcium deposit in osteoblasts and collagen in the fibroblasts leads to decrease in the time of wound healing [44].

There are no clinical studies on the use of erbium laser in the treatment of dental patients with the impaired hemostasis, but there are several studies in vivo; for example, Campos et al. (2018) compared the results of the use of high-power lasers and traditional scalpel in the rats after the administration of anticoagulants and created conditions of intensive bleeding during frenectomy of tongue that was completely solved with the laser radiation [30]. The same scientists pointed to the lack of evidence of basic information on the use of any lasers in patients with intra- and postoperative high risk of bleeding during oral surgery. Despite the possible priority of the laser energy for hemostasis, the complicity of tooth extraction in patients includes possible bleeding not only from soft tissues but also from the bottom and alveolar walls, which require other working modes of laser.

The use of erbium can significantly reduce the risk of late bleeding in patients with impaired platelet hemostasis, making it possible to carry out surgical manipulation in an outpatient dental setting without prolonged medical preparation and provide stimulation of alveolar epithelization and reduce the number of pathogenic microorganisms. In some cases, the use of an erbium laser successfully solves the problem of providing emergency surgical dental care even in patients with resistant forms of the 
disease and the manifestation of hemorrhagic syndrome [45-49].

\section{Conflict of interest}

Authors declare the absence of conflict of interest.

\section{Acknowledgments}

We appreciate the help of our colleagues and University.

\section{References}

1 Volkova AM. Clinical oncohematology. M.-Medicine; 2001. p. 576 [In Russian].

2 Psaila B, Bussel JB. Immune Thrombocytopenic Purpura. Hem/Onc Clin of North Am 2007;21(4):743-59. https:// doi.org/10.1016/j.hoc.2007.06.007.

3 Deepti NCR. Thrombocytopenia. Bleeding Dis. 2017;45(4): 221-4.

4 Rasaratnam L, Chowdary P, Pollard D, Subel B, Harrington C, Darbar U. Risk-based management of dental procedures in patients with inherited bleeding disorders: Development of a Dental Bleeding Risk Assessment and Treatment Tool (DeBRATT). Haemophilia 2017;23(2):247-54. https://doi.org/ 10.1111/hae.13122.

5 Anderson J, Brewer A, Creagh D, Hook S, Mainwaring J, McKernan A, et al. Guidance on the dental management of patients with haemophilia and congenital bleeding disorders. Br Dent J 2013;215(10):497-504. https://doi.org/10.1038/ sj.bdj.2013.1097.

6 Cocero N, Bezzi M, Martini S, Carossa S. Oral surgical treatment of patients with chronic liver disease: assessments of bleeding and its relationship with thrombocytopenia and blood coagulation parameters. J of Or and Maxillofac Surg 2017;75(1):28-34. https://doi.org/10.1016/j.joms.2016.08.033.

7 Blickstein D. Treatment of immune thrombocytopenic purpura in adults: update. Harefuah 2019;158(3):196-9.

8 Karimi O, Goorhuis A, Schinkel J, Codrington J, Vreden S, Vermaat J, et al. Thrombocytopenia and subcutaneous bleedings in a patient with Zika virus infection. Lancet 2016; 387(10022):939-40.

9 Din B, Wang X, Shi Y, Li Y. Long-term effect of high-dose dexamethasone with or without low-dose dexamethasone maintenance in untreated immune thrombocytopenia. Acta Haem 2015;133:124-8.

10 Nomura S. Advances in diagnosis and treatments for immune thrombocytopenia. Clinical Medicine Insights: Blood Dis 2016; 9. https://doi.org/10.4137/FCMBD.S39643. CMBD-S39643.

11 Rodeghiero F, Stasi R, Gernsheimer T. Standardization of terminology, definitions and outcome criteria in immune thrombocytopenic purpura of adults and children: report from an international working group. Blood 2009;113:2386-93. https://doi.org/10.1182/blood-2008-07-162503.

12 Labarque V, Van Geet C. Clinical practice: immune thrombocytopenia in paediatrics. Eur J Pediatr 2014;173:163-72. https://doi.org/10.1007/s00431-013-2254-6.

13 Ozkan MC, Sahin F, Saydam G. Immune thrombocytopenic purpura: new biological therapy of an old disease. Curr Med Chem 2015;22:1956-62. https://doi.org/10.2174/ 0929867322666150319102830 .

14 Stasi R, Del Poeta G, Stipa E. Response to B-cell depleting therapy with rituximab reverts the abnormalities of T-cell subsets in patients with idiopathic thrombocytopenic purpura. Blood 2007;110:2924-30. https://doi.org/10.1182/blood-200702-068999.
15 Stasi R. Rituximab in autoimmune hematologic diseases: not just a matter of B cells. Semin Hematol 2010;47:170-9. https:// doi.org/10.1053/j.seminhematol.2010.01.010.

16 Aster RH, Curtis BR, McFarland JG, D.W. Bougie Druginduced immune thrombocytopenia: pathogenesis, diagnosis, and management. J of Thromb and Haem 2009;7(6):911-8.

17 Mithoowani S, Gregory-Miller K, Goy J, Miller M, Wang G, Noroozi N, et al. High-dose dexamethasone compared with prednisone for previously untreated primary immune thrombocytopenia: a systematic review and meta-analysis. Lancet Haematology 2016;3:e489-96.

18 Cines D, Wasser J, Rodeghiero F, Chong BH, Steurer M, Provan D, et al. Safety and efficacy of romiplostim in splenectomized and nonsplenectomized patients with primary immune thrombocytopenia. Haematologica 2017;102:1342-51.

19 Bussel JB, Mahmud SN, Brigstocke S, Torneten SM. Tapering eltrombopag in patients with chronic ITP: how successful is this and in whom does it work? Blood 2015;126:1054.

20 Patel S, Perry MM, Spolarich AE. Oral surgery in a patient with cirrhosis and thrombocytopenia: a case report. Spec Care Dentist 2016;36:93-8. https://doi.org/10.1111/scd.12150.

21 Soltani R, Haghighat A, Fanaei M, Asghari G. Evaluation of the effect of green tea extract on the prevention of gingival bleeding after posterior mandibular teeth extraction: a randomized controlled trial. Evidence-based Compl and Alt Med 2014;2014:4. https://doi.org/10.1155/2014/857651. Article ID 857651.

22 Schaffer R, Duong ML, Wachter B, Arana E, Frances D. Access to dental care for people with bleeding dis bleeding disorders: survey results of hemophilia treatment centers in the U.S. Spec Care in Dent 2016;36(6):295-9. 2016.

23 Rashidi A, Blinder MA. Combination therapy in relapsed or refractory chronic immune thrombocytopenia: a case report and literature review. Clinical Pharmacology \& Therapeutics 2016;41:453-8.

24 Doobaree IU, Nandigam R, Bennett D, Newland A, Provan D. Thromboembolism in adults with primary immune thrombocytopenia: a systematic literature review and meta-analysis. European Journal of Haematology 2016;97:321-30.

25 Braidy H. Review of Thrombocytopenia and Perioperative Management in dentistry. Hemostasis in Dentistry 2018: $39-52$.

26 Tarantino MD, Fogarty PF, Shah P, Brainsky A. Dental procedures in 24 patients with chronic immune thrombocytopenia in prospective clinical studies of eltrombopag. Platelets 2015;26(1):93-6.

27 Najeeb S, Khurshid Z, Zafar MS, Ajlal S. Applications of light amplification by stimulated emission of radiation (lasers) for restorative dentistry. Medical Principles and Practice 2016; 25(3):201-11.

28 Najeeb S, Khurshid Z, Zohaib S, Najeeb B, Qasim SB, Zafar MS. Management of recurrent aphthous ulcers using lowlevel lasers: a systematic review. Medicina 2016;52(5):263-8.

29 Krikun EV, Blashkova SL. Diode laser in dental practice. Kazanskii meditsinskii journal 2017;98(6):1023-8 [In Russian]

30 Campos FHDO, Ferreira LB, Romano MM, Moreira MS, Eduardo CDP, Ramalho KM. Immediate laser-induced hemostasis in anticoagulated rats subjected to oral soft tissue surgery: a double-blind study. Braz Or Res 2018;32. https:// doi.org/10.1590/1807-3107bor-2018.vol32.0056.

31 Russeau AP, Manna Biagio. Bleeding Time. 2020. Bookshelf ID: NBK537233PMID: 30725918.

32 Key N, Geng Jian-Guo, Bach RR. Tissue Factor; from Morawitz to Microparticles. Trans Am Clin Climatol Assoc 2007;118: 165-73.

33 Larionova E, Tarasenko S, Morozova E, Diachkova E. Use of erbium laser in the treatment of patient with acute purulent periostitis while presence of resistant form of primary immune thrombocytopenia. Case Rep in Dent 2019. https:// doi.org/10.1155/2019/8260605. Article ID 8260605. 
34 Provan D, Stasi R, Newland AC, Blanchette VS, Bolton-Maggs $\mathrm{P}$, Bussel JB, Chong BH, Cines DB, Gernsheimer TB, Godeau $B$, et al. International consensus report on the investigation and management of primary immune thrombocytopenia. Blood 2010;115:168-86.

35 Eick S, Meier I, Spoerlé F, et al. In vitro-activity of Er: YAG laser in comparison with other treatment modalities on biofilm ablation from implant and tooth surfaces. PLoS One 2017; 12(1):e0171086. https://doi.org/10.1371/journal.pone.0171086.

36 Sanz-Sánchez I, Ortiz-Vigón A, Herrera D, Sanz M. Microbiological effects and recolonization patterns after adjunctive subgingival debridement with Er:YAG laser. Clin Or Inv 2016; 20(6):1253-61.

37 Asnaashari M, Zadsirjan S. Application of laser in oral surgery. J of Las in Med Scien 2014;5(3):97-107.

38 Risovanniy SI, Risovannaya ON, Masichev VI. Laser dentistry. Krasnodar: Kuban-kniga; 2005. p. 276 [In Russian].

39 Cobb CM. Lasers in Periodontics: a review of the literature. Periodontal 2006;77(4):545-64. https://doi.org/10.1902/ jop.2006.050417.

40 Glenn van As. Erbium lasers in dentistry. The Dent clin of North Am 2004;48:1017-59. https://doi.org/10.1016/ j.cden.2004.06.001.

41 Knappe V, Frank F, Rohde E. Principles of Lasers and Biophotonic effects. Photomed and Las Surg 2004;22(5):411-7. https://doi.org/10.1089/pho.2004.22.411.

42 Romeo U, Libotte F, Palaia G, Tenore G, Galanakis A, Annibali S. Is Er: YAG laser vs conventional rotary osteotomy better in the post-operative period for lower third molar surgery. Randomized split mouth clinical study. J of Or \& Maxillofac Surg 2015;73:211-8.

43 Convissar RA. Principles and Practice of Laser Dentistry. 2nd ed. St. Louis, Missouri: Elsevier; 2015. p. 26.

44 Najeeb S, Al-Quraini AAA, Almusallam HAA, Zafar MS, Khurshid Z. Effect of laser treatment on outcomes of tooth replantation-a systematic review. Journal of Taibah University Medical Sciences 2020. https://doi.org/10.1016/ j.jtumed.2020.03.008. In press.

45 Kale LN, Garde JB, Garde SS, Gupta P. Evolution, and applications of lasers in oral and maxillofacial surgery. J of Dent and Allied Scien 2017;1:28-31.

46 Campos F, Ferreira L, Romano M, Moreira MS, Eduardo CP, Ramalho KM. Immediate laser-induced hemostasis in anticoagulated rats subjected to oral soft tissue surgery: a doubleblind study. Brazil Or Res 2018;32. https://doi.org/10.1590/ 1807-3107bor-2018.vol32.0056.

47 Eslami H, Eslami K. Laser applications in oral surgery: review article. European journal of pharmaceutical and medical research 2016;3(11):194-8.

48 Kaur A, Misra N, Umapathy D, Shivakum G. Effectiveness of soft tissue diode laser in treatment of oral mucosal lesions. Journal of Indian Acad of Or Med and Radiol 2017;29(3): 238-41. https://doi.org/10.4103/jiaomr.JIAOMR_58_16.

49 Vitruk P, Levine R. Hemostasis and Coagulation with Ablative Soft-Tissue Dental Lasers and Hot-Tip devices. Inside Dent 2016;12(8):37-42. 